\title{
Bergson em cena ${ }^{1}$ Bergson on the scene
}

Juliano Casimiro de Camargo Sampaio ${ }^{2}$ 


\section{Resumo}

Este artigo apresenta as noções de conhecimento intelectual, instintivo e intuitivo desde Bergson e os discute no campo da docência em teatro na educação básica. Metodologicamente, opera-se revisão crítica da literatura especializada, com fins de se encontrar fissuras nas proposições do filósofo que nos permitam pensar avanços para o campo da docência em teatro. Resulta desta iniciativa, que o conhecimento que buscamos em nossas proposições para o ensino de teatro é aquele tomado por Bergson como conhecimento intuitivo. Entretanto, ainda que seja o conhecimento intuitivo aquele almejado nas práticas de referência, ele é raro, de difícil acesso, e, no mais das vezes, exige experimentações intensas em relação ao conhecimento generalizado e abstrato proveniente da inteligência.

Palavras-Chave: Ensino de teatro; pedagogia teatral; conhecimento; intuição; Bergson

\section{Abstract}

This article presents the notions of intellectual, instinctive and intuitive knowledge proposed by Henri Bergson and discusses them in the field of teaching of drama in institutionalized Brazilian basic education. Methodologically, a critical revision of the specialized literature is conducted in order to find fissures in the propositions of the philosopher that allow us to think advances for the field of teaching in theater. It results from this initiative that the knowledge we seek in our propositions about teaching of drama in Brazilian basic education is that which Bergson takes as an intuitive knowledge. However, although it is intuitive knowledge that is sought in reference practice, it is rare, difficult to access, and often requires intense experimentation in relation to generalized and abstract knowledge from intelligence.

Keywords: Teaching of drama; Theatrical Pedagogy; Knowledge; Intuition; Bergson

\footnotetext{
1 Este texto é parte dos resultados de pesquisa pós-doutoral em educação do autor, com supervisão da professora doutora Marcia Maria Strazzacappa Hernandez. Sua versão preliminar foi apresentada no Congresso Internacional de Fenomenologia, Educação e Arte (UFSJ - 2017), sob o título: Fenomenologia da Intuição, corpo e ensino: $O$ ensino de teatro na educação básica brasileira, com apoio da Propesq-UFT.

2 Professor Adjunto Doutor Universidade Federal do Tocantins (UFT) - Licenciatura em teatro e PPG Letras. juliano.casimiro@uft.edu.br
} 


\section{$(\mathrm{Re})$ Conhecer}

Os vocábulos conhecimento, reconhecimento, conhecer, reconhecer, são abundantes quando se trata do campo da educação. Muitas vezes aparecem sem qualquer definição conceitual ou nocional precisa. Ainda assim, não raras são as buscas por caminhos, metodologias, instrumentos didáticos, que permitam construir, veicular, valorizar determinados conhecimentos, na prática educacional. Ou seja, independente de perspectiva, corrente didático-metodológica ou filosofia adotada, há sempre uma busca pelos caminhos mais adequados a conhecimentos específicos, que são valorados positivamente para diversos fins. Como afirma Trevisan (1995, p. 13), "[...] toda teoria da educação supõe uma teoria do conhecimento. Não podemos falar de educação, enquanto processo, ignorando as raízes gnosiológicas que lhe dão sustentação". Bergson (1964) vai além e propõe que não se deveria separar teorias do conhecimento e vida, já que são essencialmente inseparáveis. Do que podemos extrair a afirmação de que não há efetiva teoria da educação, quando a vida, aquela cotidiana, não é seu objeto e seu fim. A partir de que chegamos ao objetivo deste artigo: pensar no ensino de teatro a pessoa em sua vida cotidiana, como foco e finalidade das práticas e metodologias adotadas na educação.

Johanson $(2005 ;$ 2014) afirma que, em Bergson, conhecer significa criar. Não se trata de descobrir algo que já está dado no mundo (desvelamento), senão de atualizar a realidade da vida; em suma, inventá-la. Ao se adotar a forma de conhecimento mais comum à cotidianidade, a inteligência, Bergson (2013) explicita que conhecer implica em extrair o que comumente é tomado por estabilidade e por imutabilidade no fluxo contínuo, constante mudança, das coisas. Nessa direção, a busca mais corriqueira é por acessar e categorizar aquilo que pode se tornar, e provavelmente se tornará, regra geral sobre a qual apoiamos nossas condutas.

Como aponta Pinto (2010), desde Bergson, ainda que o conhecimento fruto da inteligência seja bastante oportuno para a vida cotidiana, não devemos nos contentar com ele, já que ele nos dá apenas acesso parcial ao fluxo de movimento de que a natureza do homem e das coisas do mundo é constituída. O conhecimento fruto das ações representacionais da inteligência nos permite apenas contato com aquilo que se repete nas coisas. O que é sua essência e particularidade não assume real importância nos caminhos da ciência inteligente (Bergson, 1964).

É evidente que o filósofo aceita que nossa inteligência, nossos pensamentos abstratos e caminhos de entendimento das coisas do mundo, fazem parte da natureza e do movimento constante que a compõe. Ainda assim, nossa inteligência será sempre menor do que a natureza e limitada no que nos confere qualquer autonomia para conhecê-la (a natureza) em profundidade. Buscar ampliar o que tomamos por caminhos e naturezas de conhecimento significa, para Bergson (2013), nos dar a chance de tentar abarcar um pouco mais da natureza mesma, um pouco além do que a inteligência nos proporciona. Ainda que nunca conseguiremos abarcar a totalidade da natureza, pelo menos pelos caminhos já experimentados e documentados. Isto porque, ela sempre será um contínuo movimento, mutabilidade constante, fluxo ininterrupto. Bergson assevera que são as ações humanas não utilitárias, como a arte, que nos permitem algum avanço nessa relação de conhecibilidade entre homem e 
natureza (Johanson, 2005; 2014), ao adentrar o campo da intuição (Bergson, 1964; 2013). É desde este aspecto que emerge nosso interesse na filosofia de Bergson para se pensar o ensino de teatro.

As diferentes naturezas de conhecimento não produzem diferentes naturezas de consciência. A experiência artística, portanto, não faz surgir uma consciência estética que é outra em relação à consciência cotidiana. Trata-se de uma mesma consciência, fenomenologicamente única, que passa a operar de modos diversos e, portanto, chega a conhecimentos igualmente diversos. A consciência estética, assim, é a consciência para além dos ditames da inteligência, ainda que sempre vinculada a ela (Johnason, 2005). Em arte, "[...] nos diz Bergson, busca-se, antes de tudo, afastar a consciência dos hábitos intelectuais, para em seguida deixar-se levar pelo ritmo e pela pulsação [...]" (Johanson, 2014, p. 123) das coisas do mundo, que marcam a essência do conhecimento intuitivo. Todavia, ainda que a intuição faça emergir das relações com as coisas outras naturezas de conhecimento, é o instinto que se contrapõe, efetivamente, ao conhecimento fruto da inteligência (Bergson, 1964). Entretanto, ele não é, e tampouco o pode ser, para o filósofo, o conhecimento focal das experiências artísticas.

Bergson propõe com o conhecimento intuitivo, comum à experiência artística, um retorno ao imediato. Algo como suspender os conhecimentos generalizados por perspectivas teóricas como o realismo e o idealismo e voltar-se para aquilo que a experiência mesma nos faz sentir, nos dá a perceber (Prado Junior, 1989). Este contato mais imediato com a matéria é que configura a possibilidade de acesso ao movimento e à mutação constante das coisas, conhecimento intuitivo por excelência e busca incessante nos processos artísticos (Bergson, 2011).

O conhecimento fruto da intuição é aquele que busca compreender mudanças qualitativas no todo da coisa e não em suas partes constituintes isoladamente (Pinto, 2010). Em se tratando de experiência artística, se a mudança qualitativa se restringe ao espaço da criação, ou seja, não invade a vida da pessoa, ela, de fato, não se torna uma mudança essencial, senão uma mudança pontual, que pode ser compreendida pelo artificial isolamento do comportamento humano. Nesta direção, mesmo a experiência artística privilegiaria o conhecimento proveniente das ações da inteligência.

Mas nossa consciência não se contenta em conhecer. Ela se esforça em direção ao reconhecimento. Segundo Bergson, reconhecimento é um fenômeno de ordem motora. Reconhecer é evocar um conjunto organizado motor (nascente) em relação à coisa. Ou seja, o reconhecimento de objetos usuais, por exemplo, se dá na medida de nossa capacidade de nos servirmos deles. "Mas saber servir-se dele[s] é já esboçar os movimentos que se adaptam a ele[s], é tomar uma certa atitude ou pelo menos tender a isso em função daquilo que os alemães chamaram 'impulsos motores" (Bergson, 2011).

Bergson (2011) propõe a partir dos impulsos motores que primeiro exercemos o reconhecimento e depois o pensamos. Ou seja, a dimensão cognitiva do reconhecimento é posterior à sua dimensão sensível. É por meio da sensualidade que a pessoa se torna capaz de reconhecer algo. Caberia à memória a construção da dimensão cognitiva subsequente do reconhecimento. O filósofo propõe que o reconhecimento motor se dá por distração: é a dimensão automática do reconhecimento; enquanto que a ação da memória lhe atribui dimensão atenta. Ainda assim, uma e outra dimensões começam sempre pela motricidade. 
Mas, enquanto no reconhecimento automático nossos movimentos prolongam nossa percepção para obter efeitos úteis e nos afastam assim do objeto percebido, aqui [na percepção atenta], ao contrário, eles nos reconduzem ao objeto para sublinhar seus contornos (Bergson, 2011, p. 111). ${ }^{3}$

Para Pinto (2010), desde Bergson, o corpo só pode armazenar alguma recordação na forma de dispositivo motor. Há, portanto, necessidade de ampliação dos dispositivos motores em relação ao mundo. Quanto mais restritos forem os dispositivos, por repetição de experiências ou por limitação das experiências ou, ainda, por qualquer outra razão, os objetos e as coisas do mundo só serão capazes de solicitar movimentos da pessoa quando recorrerem a esse repertório de dispositivos já estabelecidos em forma de hábito. Nas artes, por exemplo, o trato com materialidades pode ser um caminho muito favorável para a expansão de qualidades e de repertórios de dispositivos motores. Dado que o reconhecimento atento também surge no âmbito motor. Quanto mais amplo for o leque de ações motoras nascentes que um objeto ou situação possa fazer emergir na pessoa, maior será a gama de possibilidades das ações das memórias independentes.

De acordo com Bergson (2011), o passado sobrevive tanto por mecanismos motores como por lembranças independentes (p. 84); o reconhecimento de objeto se faz por ações quando procede do objeto e por representações quando emana do sujeito (p. 84); e se passa das lembranças dispostas ao longo do tempo aos movimentos que dispõem as ações nascentes ou possíveis no espaço (p. 85). Assim, imagem-percepção (sensual) e imagem-lembrança (memória independente) correm num circuito fechado, uma atrás da outra (p. 117) e é esse circuito fechado que garante o reconhecimento (p. 133). Nesse sentido, o reconhecimento se produz ora por um sentimento de familiaridade que acompanha a percepção presente ou por evocação de uma percepção passada que a percepção presente parece repetir, ainda que não sejam idênticas (Bergson, 2009).

A questão do reconhecimento em Bergson nos leva a pensar a diferenciação que o autor faz entre imagem e representação, para que possamos realmente acessar suas proposições sobre os conhecimentos e os atos de reconhecimento. Para Bergson (2011), a imagem é algo entre a representação dos idealistas e a coisa dos materialistas. É a necessidade de movimento que a magem produz sobre todas as outras imagens que a distingue da representação. A construção da representação é uma redução da imagem a um quadro, que deixa de insuflar movimento às outras imagens, inclusive ao corpo, que é a imagem prevalente sobre todas as outras.

$\mathrm{O}$ que a distingue, enquanto imagem presente, enquanto realidade objetiva, de uma imagem representada é a necessidade em que se encontra de agir por cada um de seus pontos sobre todos os pontos das outras imagens, de transmitir a totalidade daquilo que recebe, de opor a cada ação uma reação igual e contrária, de não ser, enfim, mais do que um caminho por onde passam em todos os sentidos as modificações que se propagam na imensidão do universo. (Bergson, 2011, p. 33)

3 Grifos do original. 
Vale ressaltar que a imagem só é extensiva à lembrança na medida dos movimentos nascentes. Antes desses ou sem eles, ela é inextensiva, ou seja, representação. A representação, portanto, não é uma produção de ordem corporal. Como aponta Bergson (2011), as imagens do mundo exterior incitam meu corpo ao movimento, enquanto meu corpo devolve movimento às imagens exteriores. O corpo, portanto, é uma imagem movente que não gera representações.

Por outro lado, é importante notar que uma imagem não precisa ser percebida conscientemente para que possa mover o conjunto maior das imagens do mundo. Isto é, não é necessário que se represente, em termos da inteligência, a imagem para que ela exerça influência sobre o sistema maior das imagens, a partir das quais a mutação e o movimento constante que a pessoa é se efetiva. Assim, é o corpo, enquanto imagem movente, que é responsável primeiro pelo contato da pessoa com os movimentos e durações do mundo (outras imagens).

O corpo será sempre a imagem privilegiada da pessoa, a partir da qual as outras imagens convidarão a pessoa ao movimento, ainda que se guarde a autonomia de se escolher não agir, ou mesmo esperar. E todas as ações estão imbuídas dessa condição de fazer, esperar ou não realizar. Segundo Pinto (2010), a partir de Bergson, o corpo vai aos poucos se individualizando em relação às imagens do mundo, na medida em que a pessoa é capaz de se perceber "interiormente". Por isso, a "imagem especial", o corpo, assume um lugar privilegiado em relação às outras imagens (p. 57). São as afecções (sensações), junto com as ações, que gradativamente vão estabelecendo os limites físicos do corpo e a constituição de si como algo diferente do resto do mundo (p. 60). Isso nos permite supor que a experiência diversificada das sensações que incidem sobre o corpo e de demandas de ações para o corpo é capaz de reorganizar aquilo que a pessoa toma para si como si mesmo.

Ainda segundo Pinto (2010), a potência da percepção é reduzida pela necessidade da "imagem especial", o corpo. Ou seja, a imagem que chamamos "nosso corpo" limita a percepção. Nesse sentido, as atividades corporais de criação, evocam outras necessidades para a nossa imagem especial e com isso passam a estabelecer novos limites perceptivos. Os quais, após experimentados pela pessoa, podem integrar/constituir uma possibilidade, muitas vezes consciente, de escolha, de que trata a percepção consciente em Bergson.

As demandas do mundo cotidiano não são, em sua maioria, comparáveis às demandas do campo da criação artística. Como imagens conseguintes elas dialogam e se estendem uma à outra, mas não se reduzem, nem enquanto matéria, nem enquanto representação, ao mesmo domínio de experiência. Quando Bergson fala de demandas da imagem especial, não está necessariamente tratando de certo utilitarismo material ou funcional, que seja. As demandas variam de natureza e a sensibilidade ampliada a demandas provavelmente nos levará a ampliação dos movimentos retribuídos pela pessoa aos movimentos do mundo.

Em Bergson, a percepção dispõe do espaço na mesma proporção em que dispõe do tempo. E nisso se constitui a indeterminação da percepção, que permite via consciência exceder os limites da materialidade. Nessa direção, a resposta ao movimento demandado pelo mundo é tão variável quanto mais ampla for a indeterminação da percepção, que conjuga representação e matéria interdependentes na imagem. Para 
driblar os limites impostos pela determinação da imagem de algumas matérias, a pessoa cria centros de indeterminação, em que a consciência exerce o poder de tentar driblar os limites da matéria (Pinto, 2010). Nem todas as tentativas de driblar os limites da matéria são possíveis de serem concluídas. Há um limite pessoal, inclusive, sobre o alargamento da percepção. Nossa imagem especial, o corpo, é igualmente finita, ainda que possivelmente maior do que os dados representacionais que produzimos a respeito dela.

Como nos alerta Bergson (2013, pp. 187/188), as diversas imagens sobre uma coisa podem conduzir a pessoa à vivência da intuição, já que cada imagem colocará a outra em uma dinâmica de superação daquela primeira, ao mesmo tempo em que lutará por permanecer frente a outras. E é na esteira do que expusemos acima, que podemos afirmar, desde Bergson (2009), que a criação, portanto, é a passagem do esquema para a imagem, a partir do salto intelectual para a solução possível, do incorpóreo para o corpóreo. Ou seja, o verdadeiro acesso da intuição ao mundo.

$\mathrm{O}$ escritor que faz um romance, o autor dramático que cria personagens e situações, o músico que compõe uma sinfonia e o poeta que compõe uma ode, todos tem primeiro no espírito algo simples e abstrato, ou seja, incorpóreo [...] Trabalham sobre um esquema do todo, e o resultado é obtido quando chegam a uma imagem distinta dos elementos. (Bergson, 2009, p. 175)

\section{Inteligência: primazia da finalidade sobre a criação}

Trevisan (1995) nos alerta para o fato de que em Bergson tanto a inteligência quanto a intuição são funções voltadas para o conhecimento de algo e de reconhecimento das coisas do mundo. Dessa forma, não podemos tomar a inteligência e a cognição como sinônimos, já que a inteligência nos permite acesso apenas às representações das coisas do mundo e a seus símbolos. As nossas funções cognitivas, assim, se constituem para além da inteligência, sem, é claro, independer dela. Vale ressaltar que, apesar de estabelecermos aqui um diálogo mais pontual em relação à cognição, a conhecibilidade não existe sem a afetividade.

Johanson (2014), desde Bergson, alega que existem duas fontes de instrumentalização da vida. A primeira, como se verá mais adiante neste texto, a instintiva, é de natureza orgânica e provém da natureza. A segunda, fruto das ações da inteligência, é inorgânica e se volta para a fabricação de instrumentos. Ainda que seja voltada para uma instrumentalização inorgânica da vida, a nossa inteligência foi moldada a partir do nosso campo acional e procede por intenção e cálculo (Bergson, 1964). Para o filósofo, a ação é demandada pelo mundo e pelas pessoas, enquanto que a especulação seria algo como um luxo a que as pessoas se dedicam.

O utilitarismo acional que recobre a inteligência, ainda que se apoie em hábitos, não constitui estruturas rígidas e estáveis. Ao contrário, a inteligência é de fato uma tendência, que age por inferências sobre a matéria inerte (Bergson, 1964). O filósofo reconhece a inteligência como uma função inata, ainda que seus mecanismos de operação se especializem ao longo da vida da pessoa e em direta relação com o campo cultural que a cerca. Aos poucos, a inteligência articula e justapõe recortes de mundo, imobilidades construídas pela própria inteligência. "A inteligência é carac- 
terizada pelo poder indefinido de decompor de acordo seja com que lei for, e de recompor seja em que sistema for" (Bergson, 1964, p. 171).

Entretanto, decomposições e recomposições não geram entre si continuidades ininterruptas como o faz a intuição. Ao contrário, por lidar com a matéria inerte, com representações e símbolos, ela busca criar estabilidades, necessárias à vida cotidiana, é bom lembrar, mas que apresentam intervalos entre as coisas do mundo. Ela opera de repouso em repouso. A imprevisibilidade é sempre rejeitada pela inteligência, porque aquela a questiona, exatamente pela falta de continuidade dessa. Portanto, pela falta de compreensão verdadeira da vida (Bergson, 1964; 2011).

A matéria, por meio das resistências que oferece à inteligência, também a forma. Para o filósofo, matéria e inteligência configuram um ciclo ininterrupto de criação de estabilidades e representações constituído de: especialização da inteligência, deformação da matéria, domínio sobre a matéria, especialização da inteligência... (Bergson, 2011). A deformação da matéria operada pela inteligência é sustentada por duas faculdades primordiais: dedução e indução. A dedução de que fala Bergson é anterior à dedução das operações dos geômetras. O filósofo considera que nossa experiência de mundo nos permite produzir deduções naturais, "[...] cuja clareza e evidência excedem as das outras deduções" (Bergson, 1964, p. 217), e, em certo sentido, as formam. Já as induções tendem a relações de semelhança e de causa e efeito. Cria-se, assim, a ilusão de que os mesmos efeitos remeteriam sempre às mesmas causas e vice-versa. Nesse tocante, o conhecimento da inteligência será sempre um conhecimento relativo (Bergson, 2013).

Na medida em que busca criar estabilidades e imobilidades para lidar com a vida em movimento, a inteligência gera uma força de tração à consciência. Ainda que essa esteja voltada para o devir, a inteligência se prende, em grande medida, ao arsenal de passado que as experiências com a matéria constroem. Mesmo que possa gerar uma sensação de diferenciação em relação às experiências do passado, a inteligência apenas reordena, reorganiza os dados das experiências, mas não cria nada de verdadeiramente novo, função atribuída pelo filósofo à intuição (Bergson, 2013).

\section{Palavras sobre o instinto}

Segundo Trevisan (1995, p. 85), em sua leitura de Bergson, inteligência e instinto caminham para lados opostos, "[...] aquela para a matéria inerte, este para a vida". Instinto, resume o leitor de Bergson, é a simpatia no sentido etimológico da palavra. Segundo Bergson (1964), a função primordial do instinto é criar e utilizar instrumentos organizados (no sentido de tornados orgânicos). Diferente da inteligência, que busca seu aperfeiçoamento no contato com a matéria para produzir instrumentos cada vez mais eficientes, ainda que inorgânicos e inorganizados.

De acordo com Pinto (2010), enquanto a inteligência cria para si hábitos por meio da exploração da matéria inerte, o instinto traz os hábitos da natureza. Ou seja, instinto é a capacidade de um ser de usar os instrumentos naturais que possui em seu próprio organismo - faculdade natural de usar um mecanismo inato. Todavia, o instinto não é uma ação inconsciente todo o tempo. Existem gradações que podem chegar a estados de consciência no tocante ao instinto. Entretanto, mesmo não 
sendo um conhecimento exclusivamente inconsciente, é para a inconsciência que o instinto tende (Bergson, 1964). Em todo caso, é na tessitura das coisas que se instala o instinto e busca construir na experiência sensível o conhecimento imediato das coisas.

Mas, como afirma Bergson (1964), o instinto não diferencia objeto, ele diferencia propriedades. Para Johanson (2014), é a ideia de morte que introduz a noção de risco para as ações da inteligência e com isso requer alguma atuação do instinto, com fins de sobrevivência. Os chamados instintos primários são, segundo o filósofo, processos vitais, que operam ancorados em certa simpatia, também no sentido etimológico, entre as espécies.

Diferente do conhecimento da inteligência, o conhecimento instintivo é pessoal e incomunicável, daí sua proximidade com a experiência do místico (Trevisan, 1995). Segundo Bergson (1964, p. 166), "há coisas que só a inteligência é capaz de procurar, mas que, por si própria, jamais encontrará. Estas coisas, só o instinto as poderia encontrar: mas nunca as procura". Então,

Em consequência disso, Bergson observa que a inteligência, por não se vincular a nenhum objeto determinado, como o instinto, tem o potencial para buscar conhecer qualquer um, mesmo os imateriais. Porém, pelo fato de se desenvolver, com um caráter eminentemente formal, a partir das necessidades práticas do homem, ela só tem dos objetos um conhecimento indireto, relativo, não conseguindo penetrar na verdadeira realidade movente da natureza. [...] O instinto, por seu lado, desenvolve-se em uma associação íntima com a duração da vida, mas não consegue ultrapassar a materialidade em direção à consciência pura. (Pinto, 2010, p. 119)

\section{Intuição: o movimento, a criação}

No meio do caminho, entre a inteligência e o instinto, encontramos a intuição. Para Bergson, ela é o único meio para se conhecer a duração interior de si e das coisas do mundo. De fato, reiteramos, intuição e inteligência, como duas funções da consciência, não diferem quanto à sua essência, senão quanto à sua função (Trevisan, 1995; Pinto, 2010; Bergson, 1964; 2009; 2011; 2013). O que a intuição guarda do instinto é sua capacidade de proporcionar experiências imediatas (Bergson, 2011), enquanto a inteligência permite que a intuição seja comunicada, adentrando o campo da linguagem (Bergson, 2013).

Em suma, a intuição é a capacidade humana de mergulhar nas coisas para tentar reconhecer nelas aquilo que as faz únicas. Enquanto a inteligência está em busca de abstrações para generalizações, a intuição busca a particularidade no manejo com as coisas do mundo (Pinto, 2010; Bergson, 2013). A intuição exige o desvinculo com as representações e uma conexão intensa com o "se fazendo"; desde que o querer e o "se fazendo" se interpenetrem mutuamente. Isto é, que a pessoa se permita à experiência para além da segurança que a estabilidade e a inércia produzidas pela inteligência são capazes de gerar (Bergson, 1964).

A instabilidade da experiência é igualmente sentida na imprecisão do conhecimento intuitivo. Por não se produzir na linguagem verbal e na matemática consciente, como a maioria dos produtos da inteligência, o conhecimento intuitivo não possui a precisão daquele conhecimento. Um e outro, nesse sentido, se tornam 
complementares. O conhecimento intuitivo questiona as formulações inteligentes e as coloca em movimento e a inteligência permite o compartilhamento e socialização do conhecimento intuitivo, o mais próximo possível da experiência, ainda que nunca dê conta de dizer o todo dessa experiência.

São os cruzamentos de imagens, no sentido que já expusemos neste texto, que permitem que a intuição seja comunicada o mais próximo possível de sua essência. A dificuldade em se comunicar a experiência da intuição se centra no fato de que a intuição se volta para a duração, dinamicidade e movimento constitutivos das coisas do mundo, e a inteligência cria estabilidades artificiais, inclusive para produzir as linguagens ordinárias (Bergson, 2013). Como aponta Trevisan (1995), a inteligência está em busca do rotineiro, do habitual, do prático, enquanto que a intuição foca a transformação, a criação, a novidade; é o instinto sem as suas obrigações de vínculo com a sobrevivência; é o instinto que adentra voluntariamente o âmbito da cognição.

A experiência heterogênea, de resistência à representação, de criação, de intuição, interfere no fluxo prático e utilitarista da experiência homogênea socialmente construída. E essa oferece resistência àquela. Nisso uma e outra são transformadoras dos percursos de cada uma (Johanson, 2014). Nesse tocante, Bergson (1964) assume que a intuição ainda que descontínua nas experiências cotidianas é devastadora para a estabilidade do conhecimento da inteligência. A descontinuidade da intuição na vida cotidiana, o filósofo atribui à consciência ter abandonado, por razões utilitaristas, uma parte importante da sua constituição, que é a intuição.

Bergson (2013) reconhece que a faculdade da intuição existe em cada um de nós, ainda que esteja encoberta pelas demandas e urgências cotidianas de dominação da matéria. A importância do exercício da intuição na cotidianidade Bergson atribui ao fato de que da intuição possa se chegar à inteligência, mas que da inteligência não se chega à intuição. O que significa dizer que a consciência só estará completa quando se operar o conhecimento das coisas do mundo desde a intuição, que se pauta no instinto, com posterior passagem à inteligência: trazida da experiência à linguagem - compartilhamento e socialização.

Por se voltar inteiramente para a duração ininterrupta da coisa, a intuição se assemelha à empatia. Como se a pessoa fosse capaz de se transportar para dentro da coisa em profundidade, para encontrar aquilo que a faz única e que é, no mais das vezes, inexpressável (Bergson, 2013).

\section{Considerações intuitivas sobre o ensino de teatro - mesmo aqui, precisamos da inteligência}

Para Bergson (1964; 2009; 2013), a arte nos desloca para o domínio da intuição na medida em que deixa de operar no campo da representação e passa a operar no âmbito da sugestão. Dessa maneira, ela nos desliga dos nossos hábitos cotidianos e nos conecta às possibilidades de originalidade e novidade na relação pessoa-matéria. O teatro, em sua especificidade, deveria operar o deslocamento em questão em dois âmbitos complementares: 1- da pessoa para com ela mesma; 2 - da pessoa para com as situações que vivencia no mundo. 
Para Pinto (2010), o problema não está em criar esquemas práticos oriundos de representações para consecução de metas ordinárias. Ao contrário, eles são necessários. O problema real está em compreender esses esquemas como propriedades das coisas e únicos meios de manipulação das coisas. O mesmo fato pode existir no campo da arte. Modos de se fazer. Jeitos corretos. Técnicas adequadas. Esse tipo de colocação é igualmente prejudicial. E se torna ainda mais prejudicial quando se pensa que o fazer teatral, artístico, por ele mesmo, já daria conta da suspensão de que fala Bergson. Equívoco muitas vezes sustentado por profissionais da área.

Nessa direção, a inserção do teatro na escola não garante, em hipótese alguma, como característica essencial da linguagem, algo que ela carregaria, independente das nossas iniciativas, e que produziria a suspensão dos hábitos cotidianos. Muito pelo contrário. A linguagem teatral pode ser igualmente um instrumento de construção de generalidades estáticas. Basta que pensemos, por exemplo, o utilitarismo do teatro jesuíta na catequização de populações ameríndias.

A inteligência, como já apontamos anteriormente, não cria. Ela reordena. Enquanto a reordenação das coisas do mundo, já sabidas, já conhecidas e já reconhecidas pela pessoa derem conta de satisfazer seus anseios, não há necessidade de suspensão das representações e generalidades. Assim, também o teatro pode ocupar lugar reordenador apenas, o que, em determinados contextos, pode ter uma valoração positiva para fins específicos. É quando as necessidades vitais e da liberdade da pessoa (que em Bergson se volta para o exercício da criação, do novo, e, acima de tudo, da vontade) não são suplantadas pela inteligência que a intuição se torna urgente. Em suma, só quando o teatro for capaz de despertar na pessoa a vontade pelo mergulho em profundidade em alguma coisa do mundo, incluindo a si mesmo, é que ele realmente se torna criativo. É nesse momento em que mundo das representações e vontade do agente não coincidem mais que o exercício da criatividade, a que Bergson chama de élan vital, se efetiva. Como afirma Pinto (2010), nessa direção, Bergson reconhece a necessidade de que se produza uma pedagogia da vontade que seja anterior à pedagogia da inteligência, ainda que não devamos abrir mão dessa última.

A experiência teatral verdadeiramente produtora de conhecimentos fruto da intuição, isto é, questionadora dos ditames da inteligência, é aquela que permite que a pessoa crie problemas para si e para as coisas. Essa é para o filósofo a metafísica da intuição. Descobrir problemas já dados no mundo e lidar com eles segue sendo um exercício da inteligência (Bergson, 2013), mesmo que o contexto de ocorrência seja o ensino e a prática teatral, artística. O que, em resumo, significa desperdiçar, na educação, a especificidade de contexto e de natureza de conhecimento possível na linguagem teatral.

Como afirma Johanson (2005), quando a metafísica da intuição adentra o campo da criação, ou melhor, pode ser reconhecido nele, a matéria suscita, instiga, convida o artista a ver nela algo que a dimensão utilitária da inteligência não veria. Então, o artista vê a coisa nela mesma e isso alicerça os movimentos centrífugos e centrípetos de que fala Bergson sobre a criação: da pessoa à coisa e da coisa à pessoa. Segundo Trevisan (1995), a educação em Bergson prevê o desenvolvimento de um estado criador que exteriorize a existência mais profunda em movimento, em corpo, em ação. 
Para Bergson (2011), a noção de corpo não é inata. Ela se constrói no confronto da permanência da imagem de meu corpo em relação às mudanças das imagens das coisas. Entretanto, se meu corpo lida quase exclusivamente com representações (conhecimentos da inteligência), cria-se a ilusão de que ele também é estático e produtor de representações. Mas, como já afirmamos anteriormente, nosso corpo, limite movente, devolve ao mundo imagens e nunca representações. O ensino de teatro, portanto, deveria proporcionar aos alunos mergulhos em profundidade nas relações com as coisas. Mergulhos que visem nas coisas àquilo que lhes faz únicas, a duração verdadeira. Com isso, deixaríamos de pensar o ensino de teatro no âmbito da espacialidade e passaríamos a exercê-lo no âmbito da temporalidade.

Segundo Pinto (2010), a duração da matéria se dá basicamente no presente, enquanto a duração da consciência articula passado, presente e futuro. A matéria se dá a ser modelada pelo desejo do ser consciente. Quanto maior for a capacidade de manipular a matéria para satisfação de suas necessidades (inteligência), maior o grau de evolução que o ser consciente chega. Contudo, a matéria se repete incessantemente. Talvez seja o dobrar da consciência desejante sobre ela que permita que a matéria se faça diferente no seu movimento de duração. E isso é do campo prioritário da arte (Pinto, 2010, p. 87). A liberdade do sujeito está exatamente na capacidade de contrair a duração da consciência (memória) para se adaptar da melhor forma possível às demandas de si e do mundo e com isso dominar o ambiente (Pinto, 2010, p. 91). O que nos parece dessa colocação, é que se de um lado há uma especialização da percepção para fins objetivos em relação à matéria, por outro, Bergson ainda sustenta, como uma das questões principais, a ideia de liberdade, que requer que pensemos que as demandas não são só provenientes da própria matéria, como também do querer da consciência. Nesse sentido, imaginamos que, se em uma mão a especialização da percepção é algo necessário à existência e evolução, na outra, a especialização que leva à exclusão de outras possibilidades e virtualidades, no sentido bergsoniano, é igualmente prejudicial. A exploração da matéria (corpo, mas não só ele) é o campo pontual para nós de função para o ensino de teatro. Se na vida extra-contexto-artístico a exploração especializada da percepção é necessária, nos contextos de criação, deve-se suspender essa percepção inteligente para termos espaço e condições de experimentar o que é acessar a matéria, priorizando nossa intuição ou mesmo as afecções de que fala o próprio Bergson.

Já que a memória não é só consciência (pensar o corpo, sua sensualidade e sua motricidade), até os seres mais rudimentares tem algum grau de liberdade. Entretanto, para Bergson, não é a inteligência que garante a verdadeira liberdade do ser. É a sua exploração, para além dos hábitos, numa relação cada vez mais próxima de um contato imediato com a duração da coisa, algo que não atenda às demandas funcionais do ser e da coisa, mas sim, da ampliação das potências e virtualidades presentes na relação (Pinto, 2010). Como podemos observar, o próprio Bergson abre a possibilidade de se pensar a importância de experiências que transcendam as demandas funcionais. E só a partir disso é que podemos falar pontualmente do exercício da liberdade humana. Que outro campo além das artes ou melhor que as artes podem propiciar essa suspensão de demandas e esse movimento de durar na duração da coisa? 
Segundo Pinto (2010), a percepção em Bergson é essencialmente indeterminada e vai se especializando (determinando) ao longo de demandas de ação do corpo. Nessa direção, as experiências com e em teatro podem retomar o caminho no sentido da indeterminação do querer de que fala o autor como original à percepção. Enquanto a especialização da percepção em direção à uma percepção consciente é um movimento centrípeto, a experiência artística pode produzir um movimento centrífugo da percepção em direção à sua indeterminação essencial. Essa nossa afirmação, vai ao encontro da ideia bergsoniana de que a cristalização de hábitos no cotidiano limita cada vez mais o campo de respostas e demandas corporais, portanto, da própria percepção.

Nas palavras de Bergson (2013, p. 153), "a que nos aponta a arte se não a nos mostrar, na natureza e no espirito, fora de nós e em nós, coisas que não afetam de maneira explícita nossos sentidos e nossa consciência?". Mas, de fato, qual o conhecimento que a criação artística maneja? Para Bergson, toda criação maneja o conhecimento da mudança, do movimento, da duração. Os repousos de que trata a inteligência são artificialidades com o que a arte não deveria se conformar. Ensino de Teatro, nesses termos, deveria ser, antes de qualquer coisa, incentivo ao encontro com a duração de si e das coisas do mundo, aquilo que sempre se transforma para tornar cada coisa única, ainda que possa ser reduzida, pelo exercício da inteligência, a categorias e representações, para adentrar princípios de comunicação, por exemplo. Ou seja, sendo o teatro uma linguagem, a experiência intuitiva teatral só poderá ser comunicada via inteligência. Até aqui precisamos da inteligência.

Por fim, o que buscamos com o ensino de teatro quando adentramos sua dimensão temporal, da intuição, portanto, é experimentar nos fenômenos um tempo que não pode ser descartado para que esses fenômenos sejam alcançados em sua inteireza. É o tempo da mutabilidade das formas, que podemos até acelerar por mecanismos específicos, mas não podemos saltar para um momento depois deles, sem que eles sejam efetivados.

\footnotetext{
Quando alguém quer preparar um copo de água com açúcar [...], é forçoso esperar que o açúcar se dissolva. Esta necessidade de esperar é o fato significativo. Expressa o fato de que, ainda que se possa recortar no universo sistemas para os quais o tempo é somente uma abstração, uma relação, um número, o universo mesmo é outra coisa. (Bergson, 2013, p. 25)
}

\section{Referências}

BERGSON, Henri. A energia spiritual. São Paulo: Martins Fontes, 2009.

BERGSON, Henri. A evolução criadora. Rio de Janeiro: Editora Delta, 1964.

BERGSON, Henri. El pensamiento y lo moviente. Buenos Aires: Cactus, 2013.

BERSGON, Henri. Matéria e memória. São Paulo: Martins Fontes, 2011. 
JOHANSON, Izilda. Arte e Intuição: a questão estética em Bergson. São Paulo: Associação Editorial Humanitas, FAPESP, 2005.

JOHANSON, Izilda. Bergson: pensamento e invenção. São Paulo: Editora FAP-UNIFESP, 2014.

PINTO, Tarcísio Jorge Santos. O método da intuição em Bergson e sua dimensão ética e pedagógica. São Paulo: Edições Loyola, 2010.

PRADO JUNIOR, Bento. Presença e campo transcendental: consciência e negatividade na filosofia de Bergson. São Paulo: Edusp, 1989.

TREVISAN, Rubens Muríllio Tavares. Bergson e a educação. Piracicaba: Editora UNIMEP, 1995.

Recebido em: 01/12/2017

Aprovado em: 06/05/2018 